\title{
Chemometric Assisted Spectrophotometric Method Development for Evaluation of Torsemide and Eplerenone in their Combined Tablet Dosage Forms
}

\author{
Madhuri A*, Dipti Patel \\ Department of Quality Assurance, Shree S.K. Patel College of Pharmaceutical Education and Research, Ganpat Vidyanagar, \\ Mehsana, Gujarat, INDIA.
}

\begin{abstract}
Aim: In a present work two drugs Torsemide and Eplerenone were estimated from their combined tablet dosage forms by applying chemometric assisted spectrophotometric method. Methods: The methods are based on chemometrics a (multivariate) method which includes classical least square (CLS) and inverse least square (ILS). These methods were employed for simultaneous determination of Torsemide and Eplerenone in tablet dosage forms without any prior separation of components. For these methods the overlapping spectra of two drugs not subjected any conversions. The data processing of chemometric was accomplished by using software named Chemometrics Toolbox 3.02 which is associated with MATLAB 6 and excel. Results: The results obtained from CLS and ILS methods were compared statistically. These chemometric methods were applied for the determination of these two drugs in their marketed tablet dosage form without any prior separation procedure of the drugs. The mean percent recoveries and values of relative standard deviation for these two methods were found to be 99.72/0.536 for Torsemide and 100.06/0.384 for Eplerenone. Conclusion: The two chemometric methods developed can be successfully applied for the quantitative estimation of drugs from their dosage form.

Key words: Spectrophotometry, Chemometrics, Torsemide, Eplerenone, Classical least square method, Inverse least square method, Root mean square error of prediction
\end{abstract}

\section{INTRODUCTION}

The chemometric methods are useful for analysis of multi-component by the resolving their complicated spectra from mixtures of drugs. ${ }^{1}$ The chemometric methods of analysis have utilizations and excellence over traditional analytical methods for example; the mixtures of components can be appropriately estimated without separating drugs from their mixture. Other advantages are; these methods are easy in application, sensitive to smallest concentration, useful and economical in comparison to other methods of analysis used for simultaneous determination of components in multicomponent mixtures. These methods are more advantageous because while performing the calibration and analysis of drugs the concentration of other components are not interfering and also the determination of components in a mixture becomes rapid. ${ }^{2}$

Torsemide (TOR) is from loop diuretic category $^{3,4}$ and chemically it is 3-Pyridinesulfonamide, N- [[(1 methylethyl) amino] carbonyl]-4-[(3-methylphenyl) amino]1-Isopropyl- 3-[(4-m-toluidino-3-pyridyl) sulfonyl] urea $^{5}$ (Figure 1). This drug is indicated in the treatment of hypertension or edema associated with congestive heart failure, renal disease and hepatic disease.

The chemical name of Eplerenone (EPL) is methyl (1'R,2R,2'S,9'R,10'R, 11'S,15'S,17'R)-2',15'-dimethyl-5,5'-dioxo-18'oxaspiro[oxolane-2,14' pentacyclo[8.8.0.0 $0^{1},{ }^{7}{ }^{7} .0^{2}$, $\left.{ }^{7} .0^{11},{ }^{5}\right]$ octadecan]- 6'-ene-9'- carboxylate ${ }^{6}$ (Figure 2). This drug is from Steroid
Submission Date: 13-04-2021; Revision Date: 18-08-2021; Accepted Date: 26-11-2021

DOI: 10.5530/ijper.56.1.30 Correspondence:

Mrs. Madhuri Hinge Assistant Professor, ROFEL Shri G.M. Bilakhia College of Pharmacy, Vapi (West), 396191, Gujarat, INDIA. E-mail: madhuri_shreyal@ yahoo.co.in

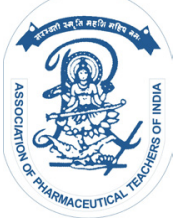

www.ijper.org 


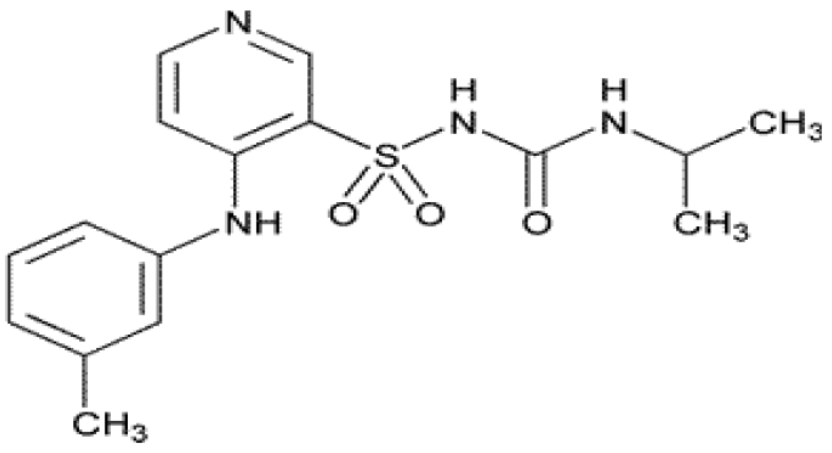

Figure 1: Structure of Torsemide.

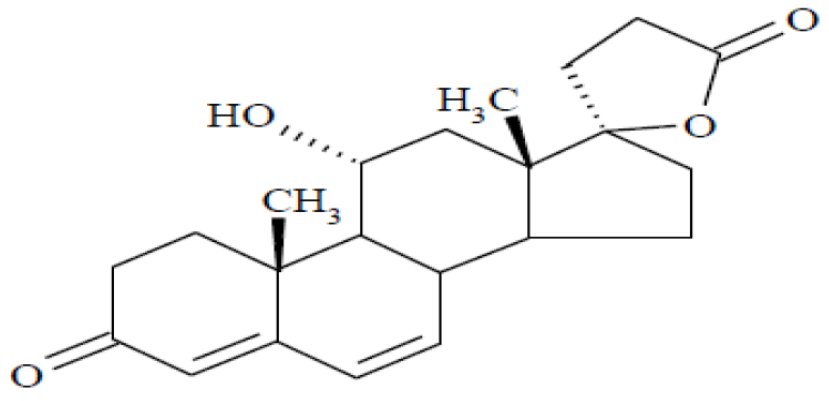

Figure 2: Structure of Eplerenone.

Lactones class, and use in treatment of Edema associated with Congestive Heart Failure. Eplerenone is act by reducing the activity of aldosterone and used with other drugs in the management of chronic heart failure. It is used as antihypertensive agent and diuretic. ${ }^{3,4}$

Torsemide is official in USP 2007, ${ }^{7}$ and Eplerenone are official in IP $2014,{ }^{8}$ and both the drugs are analysed by Liquid chromatographic method.

After extensive literature review we found that several analytical methods were reported for the determination of Torsemide and Eplerenone in single dosage forms and in combination with other drugs. The different methods are high performance liquid chromatography (HPLC), ${ }^{9-19}$ TLC and HPTLC, ${ }^{20,21}$ HPLC LC-MS, ${ }^{22,23}$ and spectrophotometry. ${ }^{24-27}$ Some UV spectrophotometric and HPLC methods, ${ }^{28-30}$ are reported for the determination of Torsemide and Eplerenone in combined tablet dosage forms. In this paper, we have reported the investigation and development of rapid analytical method for the simultaneous determination of Torsemide and Eplerenone. The methods are based on UV spectrophotometry, and the resulting overlapping spectra of drugs are processed by chemometrics. The application of chemometrics allows the interpretation of multivariate data and is very useful for the simultaneous determination of the organic components. In the present study, the two chemometric methods are successfully used for the simultaneous estimation of Torsemide and Eplerenone.

\section{MATERIALS AND METHODS}

Commercial tablets Planep-T containing $10 \mathrm{mg}$ of Torsemide and $25 \mathrm{mg}$ of Eplerenone were taken for analysis. The spectrophotometric analysis of mixture of two drugs was carried out by using a Shimadzu UV-Vis double beam spectrophotometer which is equipped with $1 \mathrm{~cm}$ quartz cells and connected to computer with UV Probe Version 2.10 software. The CLS and ILS calculations were performed in Chemometrics Toolbox 3.02 software in connection with MATLAB R2015a Software and Excel.

\section{Preparation of standard solutions and calibration}

The two drugs were measured by using spectrophotometer. The stock solution of $1000 \mu \mathrm{g} / \mathrm{ml}$ of TOR and EPL were prepared by dissolving $10 \mathrm{mg}$ of each drug in $10 \mathrm{ml}$ of methanol. Further dilutions were made in methanol to obtain concentrations ranging from $3-10 \mu \mathrm{g} / \mathrm{ml}$ for TOR and $7.5-25 \mu \mathrm{g} / \mathrm{ml}$ for EPL and their different synthetic mixtures were prepared by using the stock solutions. The zero order spectra were recorded over the wavelength range $200-400 \mathrm{~nm}$ against the solvent blank.

\section{Preparation of binary mixtures of TOR and EPL}

The binary mixtures of two drugs were prepared from the above stock solutions. The calibration set of 15 different standard solutions and validation set of 10 mixed standard solutions containing the concentrations with different quantities of TOR and EPL was prepared. The concentrations of mixed standards fall in the linearity range of two drugs. The solutions of calibration set and validation set were scanned in spectrophotometer. The absorbance data matrix was generated by measuring the absorbance at 31 wavelength points with the interval of $2 \mathrm{~nm}$ between 240 to $300 \mathrm{~nm}$ in spectral region. A calibration set of 15 different mixtures was prepared by using methanol as solvent and a multilevel multifactor design was used, for these design concentrations of TOR and EPL were taken at two different levels. Similarly a validation set of 10 different mixtures was prepared and multilevel multifactor design was applied to the concentrations of TOR and EPL at two different levels. The composition of calibration set and validation set are shown in Table 1 and Table 2. 
Table 1: Composition of Calibration set for two constituents used in CLS and ILS techniques.

\begin{tabular}{|c|c|c|}
\hline Mix. No. & TOR $(\boldsymbol{\mu g} / \mathbf{m l})$ & EPL $(\boldsymbol{\mu g} / \mathbf{m l})$ \\
\hline 1 & 3 & 15 \\
\hline 2 & 3 & 20 \\
\hline 3 & 3 & 25 \\
\hline 4 & 4 & 7.5 \\
\hline 5 & 4 & 10 \\
\hline 6 & 4 & 25 \\
\hline 7 & 6 & 10 \\
\hline 8 & 6 & 15 \\
\hline 9 & 6 & 20 \\
\hline 10 & 8 & 7.5 \\
\hline 11 & 8 & 20 \\
\hline 12 & 8 & 25 \\
\hline 13 & 10 & 7.5 \\
\hline 14 & 10 & 10 \\
\hline 15 & 10 & 15 \\
\hline
\end{tabular}

Table 2: Composition of Validation set for all two constituents used in CLS and ILS techniques.

\begin{tabular}{|c|c|c|}
\hline Mix. No. & TOR $(\boldsymbol{\mu g} / \mathbf{m l})$ & EPL $(\boldsymbol{\mu g} / \mathbf{m l})$ \\
\hline 1 & 3 & 7.5 \\
\hline 2 & 3 & 10 \\
\hline 3 & 4 & 15 \\
\hline 4 & 4 & 20 \\
\hline 5 & 6 & 25 \\
\hline 6 & 6 & 7.5 \\
\hline 7 & 8 & 10 \\
\hline 8 & 8 & 15 \\
\hline 9 & 10 & 20 \\
\hline 10 & 10 & 25 \\
\hline
\end{tabular}

\section{Preparation of sample solutions}

For performing assay, twenty tablets of brand (Planep-T) were weighed and powdered by using the mortar and pestle. An amount of the powder equivalent to $25 \mathrm{mg}$ of EPL was weighed accurately and taken in a $25 \mathrm{ml}$ calibrated volumetric flask and dissolved in methanol. The solution was sonicated and filtered by using Whatman filter paper number 41. The filtered solution was diluted up to $25 \mathrm{ml}$ with methanol. The resulting solution was further diluted with methanol of the concentration falling within calibration range. After scanning in spectrophotometer, the proposed chemometric (CLS and ILS) methods were used for determination of sample solutions.

\section{Classical least squares method}

In CLS method linear relationship between the absorbance and the concentrations of components at each wavelength were used for calculation. In this method matrix notation was formed on the basis of Beer's law model for $\mathrm{m}$ calibration standard solutions which contains 1 chemical components with spectra of $\mathrm{n}$, computed absorbance is expressed by the following equation, ${ }^{1,2}$

$$
A=C \times K+E A
$$

where $\mathrm{A}$ is the $m \times n$ matrix of calibration spectra, $C$ is the $m \times l$ matrix concentrations of component, $K$ is the $l \times n$ matrix of proportionality constants absorbanceconcentration relation and $E A$ is the $m \times n$ matrix of spectral errors or residuals which are not fitted in the model.

\section{Inverse least squares (ILS) method}

The ILS method measures concentration in relation to absorbance. It consists of the inverse of Beer's law model for $m$ calibration standards solutions with spectra of $n$ computed absorbance is given by the following equation, ${ }^{1,2}$

$$
C=A \times P+E c
$$

Where $C$ and $A$ are concentration and Absorbance as mentioned in CLS method, $P$ is matrix of $n \times l$ and depends upon calibration co-efficient of samples which are obtained from their concentrations at typical spectral intensities and $E_{c}$ is vector of errors and designated by $m \times l$.

Since in ILS method the number of wavelengths should not be more than the total number of calibration mixtures, the wavelengths for measurement were selected on basis of multiple linear regressions.

\section{RESULTS AND DISCUSSION}

Figure 3 shows the zero-order overlay spectra of TOR and EPL as well as their corresponding binary mixture in methanol. As depicted in Figure 3, the spectra of TOR and EPL are overlapped with each other. Estimation of these drugs by using simple spectrophotometric method becomes difficult; to solve this problem chemometric method can be used to determine the two compounds individually from their mixtures. To estimate the drugs in condition of overlapped spectra the chemometric calibrations methods can be used. 


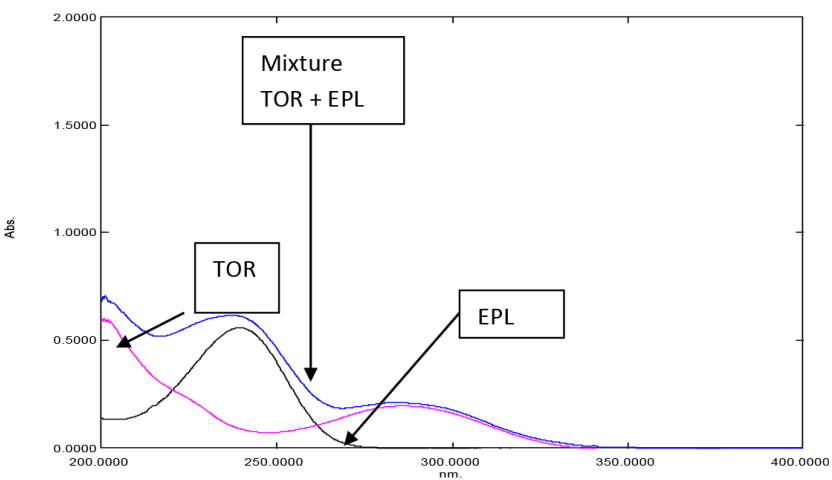

Figure 3: Overlain spectra of TOR (10 $\mu \mathrm{g} / \mathrm{ml})$, EPL $(25 \mu \mathrm{g} / \mathrm{ml})$ and mixture.

\section{Multivariate calibration in CLS and ILS method}

The calibration set was prepared consisting 15 standard mixture solutions containing the different concentrations of TOR and EPL selected randomly falling within the linearity range of two drugs. The absorbances of the prepared solutions were measured in the spectral region of $240-300 \mathrm{~nm}$ at interval of $2 \mathrm{~nm}$ and absorbance data was generated. The chemometric calibrations were performed by using the CLS and ILS algorithms and correlation between concentrations and its absorbance data. The results obtained from these methods of multicomponent analysis are depend upon the wavelength range selected, concentration of solutions of calibration set, calibration range and spectral mode used. In the CLS technique full spectrum of drugs is computed, therefore selection of wavelength is not important as all available wavelengths are used for estimation. While in ILS method the frequencies were selected on the basis of multiple linear regressions.

\section{CLS Method}

For estimation of drugs by CLS method by using the coefficient matrix $(K)$. The coefficient matrix can be calculated from linear equation obtained by plotting the absorbance data and concentration of solutions of calibration set. The coefficient matrix $(\mathrm{K})$ replaced in the linear equation system and the calibration of CLS can be presented as follow:

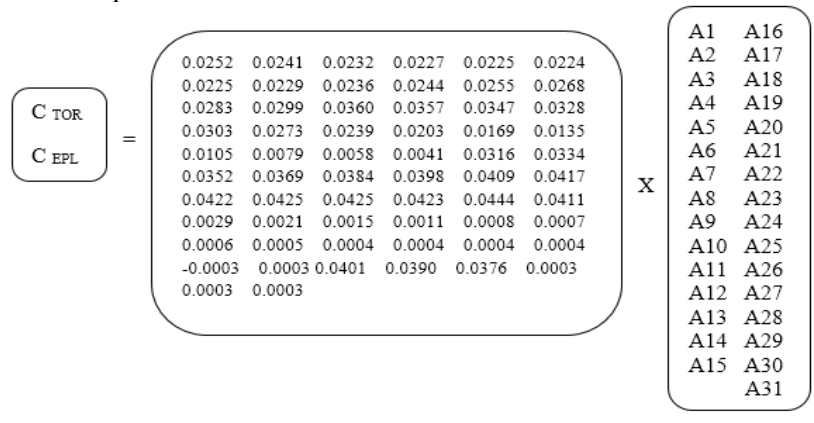

\section{ILS method}

In ILS method, the coefficient matrix (P) was used for estimation of drugs which can be determined from the linear equation by plotting the absorbance against the concentration of solutions of calibration set. From the linear equation system the value of $(\mathrm{P})$ was replaced and calibration for ILS was obtained as given below:
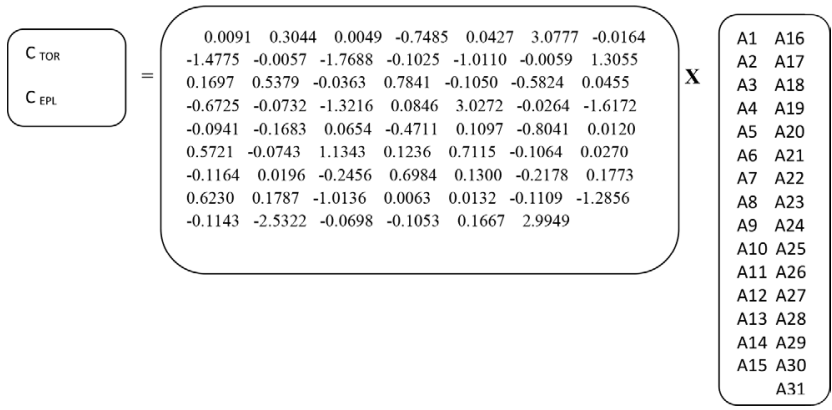

\section{Statistical parameter}

The regression model can be applied predictively and described in different ways. The chemometric methods are expressed in terms of SEP stands for standard error of prediction and SEC stands for standard error of calibration or root mean square error of prediction is expressed by formula given below;

$$
\text { RMSEP }=\sqrt{\frac{\sum_{i=1}^{N}\left(C_{i}^{\text {added }}-C_{i}^{\text {found }}\right)^{2}}{n}}
$$

In above equation, $C$ is predicted concentration of TOR and EPL in mixture and $\mathrm{n}$ is the total number of the mixtures prepared of both drugs.

The RMSEP were calculated by application of CLS and ILS methods to the validation set of the mixtures of both drugs and the results are mentioned in Table 3.

The validity of the calibration methods can be determined by estimating the two drugs simultaneously from their validation set. The result of the mean percent recovery for CLS and ILS methods for the mixed solutions of two drugs was found to be in acceptable limit. The recovery study was carried out by addition of known amounts of standard drugs to a fixed concentration of the tablet formulations. A fixed volume or concentration of the sample solution was taken and then a known volume

\begin{tabular}{|c|c|c|}
\hline Drugs & RMSEP (CLS) & RMSEP (ILS) \\
\hline Torsemide & 0.06069 & 0.05097 \\
\hline Eplerenone & 0.05097 & 0.58312 \\
\hline
\end{tabular}




\begin{tabular}{|c|c|c|c|c|c|}
\hline \multicolumn{3}{|c|}{ Torsemide } & \multicolumn{3}{|c|}{ Eplerenone } \\
\hline $\begin{array}{c}\text { Added } \\
(\mu \mathrm{g} / \\
\mathrm{ml})\end{array}$ & $\begin{array}{l}\text { Found } \\
\text { ( } \mu \mathrm{g} / \mathrm{ml})\end{array}$ & $\begin{array}{c}\% \\
\text { Recovery }\end{array}$ & $\begin{array}{l}\text { Added } \\
(\mu \mathrm{g} / \mathrm{ml})\end{array}$ & $\begin{array}{l}\text { Found } \\
(\mu \mathrm{g} / \mathrm{ml})\end{array}$ & $\begin{array}{c}\% \\
\text { Recovery }\end{array}$ \\
\hline 3 & 3.0401 & 101.34 & 7.5 & 7.4914 & 99.89 \\
\hline 3 & 2.9532 & 98.44 & 10 & 9.9842 & 99.84 \\
\hline 4 & 4.0152 & 100.38 & 15 & 14.9025 & 99.35 \\
\hline 4 & 4.0296 & 100.74 & 20 & 19.7630 & 98.82 \\
\hline 6 & 5.9707 & 99.51 & 25 & 25.3326 & 101.33 \\
\hline 6 & 6.0932 & 101.55 & 7.5 & 7.4829 & 99.77 \\
\hline 8 & 7.9642 & 99.55 & 10 & 9.8795 & 98.80 \\
\hline 8 & 7.9611 & 99.51 & 15 & 14.8325 & 98.88 \\
\hline 10 & 9.8934 & 98.93 & 20 & 19.7562 & 98.78 \\
\hline 10 & 9.8965 & 98.97 & 25 & 24.7411 & 98.96 \\
\hline \multicolumn{2}{|c|}{ Mean Recovery } & 99.89 & \multicolumn{2}{|c|}{ Mean Recovery } & 99.44 \\
\hline \multicolumn{2}{|c|}{ \%RSD } & 0.7162 & \multicolumn{2}{|c|}{$\%$ RSD } & 0.4173 \\
\hline
\end{tabular}

\begin{tabular}{|c|c|c|c|c|c|}
\hline \multicolumn{3}{|c|}{ Torsemide } & \multicolumn{3}{|c|}{ Eplerenone } \\
\hline $\begin{array}{l}\text { Added } \\
(\mu \mathrm{g} / \mathrm{ml})\end{array}$ & $\begin{array}{l}\text { Found } \\
(\mu \mathrm{g} / \mathrm{ml})\end{array}$ & $\begin{array}{c}\% \\
\text { Recovery }\end{array}$ & $\begin{array}{l}\text { Added } \\
(\mu \mathrm{g} / \mathrm{ml})\end{array}$ & $\begin{array}{l}\text { Found } \\
(\mu \mathrm{g} / \mathrm{ml})\end{array}$ & $\begin{array}{c}\% \\
\text { Recovery }\end{array}$ \\
\hline 3 & 2.9485 & 98.28 & 7.5 & 7.5161 & 100.21 \\
\hline 3 & 2.9968 & 99.89 & 10 & 9.8957 & 98.96 \\
\hline 4 & 3.9726 & 99.32 & 15 & 14.9995 & 100.01 \\
\hline 4 & 4.0048 & 100.12 & 20 & 20.2427 & 101.21 \\
\hline 6 & 5.9682 & 99.47 & 25 & 24.6914 & 98.77 \\
\hline 6 & 6.1031 & 101.72 & 7.5 & 7.5727 & 100.97 \\
\hline 8 & 7.8929 & 98.66 & 10 & 9.8767 & 98.77 \\
\hline 8 & 7.9193 & 98.99 & 15 & 15.0481 & 100.32 \\
\hline 10 & 10.1278 & 101.28 & 20 & 20.1609 & 100.80 \\
\hline 10 & 9.9513 & 99.51 & 25 & 25.1457 & 100.58 \\
\hline \multicolumn{2}{|c|}{ Mean Recovery } & 99.72 & \multicolumn{2}{|c|}{ Mean Recovery } & 100.06 \\
\hline \multicolumn{2}{|c|}{$\%$ RSD } & 0.5367 & \multicolumn{2}{|c|}{$\%$ RSD } & 0.3849 \\
\hline
\end{tabular}

*Mean of three individual determinations

of working standard solutions was spiked. Finally the volume in volumetric flask was adjusted with methanol and mixed. Then the resulting mixture solutions were analyzed and recoveries of both drugs in chemometric methods were assessed. The results obtained were found to be closer to expected values. The mean of percentage recoveries and RSD values of the mentioned methods were calculated and are depicted in Table 4 and 5. The result of recovery study was closer to $100 \%$ and RSD was found to be less than 2 which indicate that the methods were validated successfully. The result also indicates that
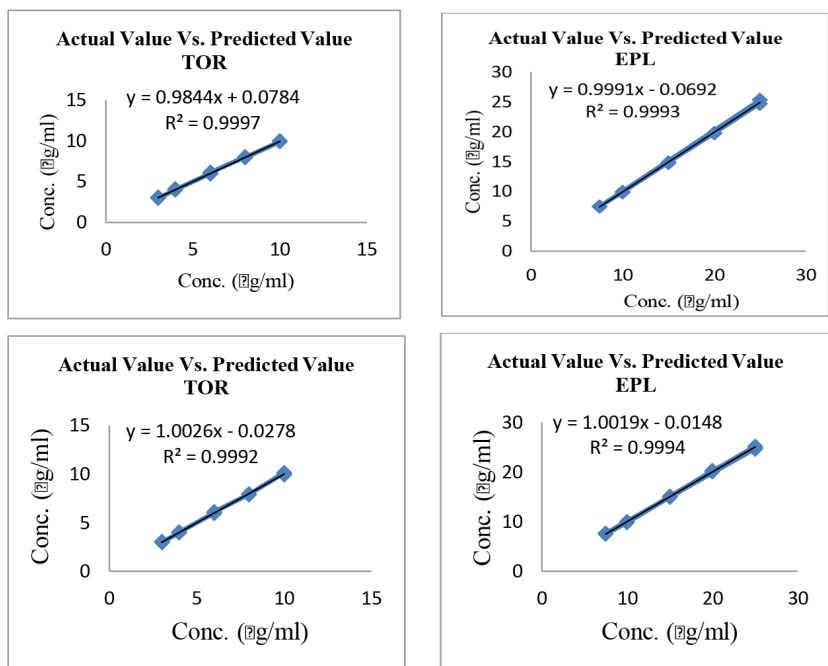

Figure 4: CLS - Expected vs. Predicted Concentration of TOR and EPL, ILS - Expected Vs. Predicted Concentration of TOR and EPL.

the proposed methods are accurate and excipients are not interfering in estimation of two drugs. The linearity of the proposed chemometric method for determination of TOR and EPL was assessed by analysing a series of different concentrations of standard drug. The linearity for both the methods were determined by taking different concentrations of two drugs and was found to be range of $3-10 \mu \mathrm{g} / \mathrm{ml}$ for TOR and $7.5-25 \mu \mathrm{g} / \mathrm{ml}$ for EPL. Linearity was performed repeatedly thrice.

The methods involve the comparison between predicted concentrations of the drugs in all sample mixture solutions and the actual concentrations taken of the drugs in all mixture solutions of validation set. On the basis of this comparison the root mean square error of cross validation (RMSECV) was computed for both the methods. The error in the predicted concentrations can be estimated from the values of RMSECV. The model is very important for quantitation of drugs by CLS and ILS calibration methods. The methods were validated by analysing and predicting the concentration of drugs in validation set which is different from the calibration set used for method development. The two methods were evaluated for predictive abilities by plotting the graph of predicted concentrations verses the actual known concentrations (Figure 4). Figure 4 indicate the adequate concurrence between the actual concentration and predicted concentration of drugs. A different characteristic test was performed by plotting the graph of residuals concentration verses predicted concentration. In Figure 5, the residual values are randomly distributed near zero line indicating compatibility of methods. The values of correlation coefficient $\left(\mathrm{r}^{2}\right)$ and slope were 
found to be good for both drugs in the validation set by CLS and ILS optimized methods and indicates that the both methods have good predictive abilities.

\section{ASSAY OF MARKETED FORMULATION}

Total twenty tablets of each brand were taken for assay. Tablets were accurately weighed and crushed
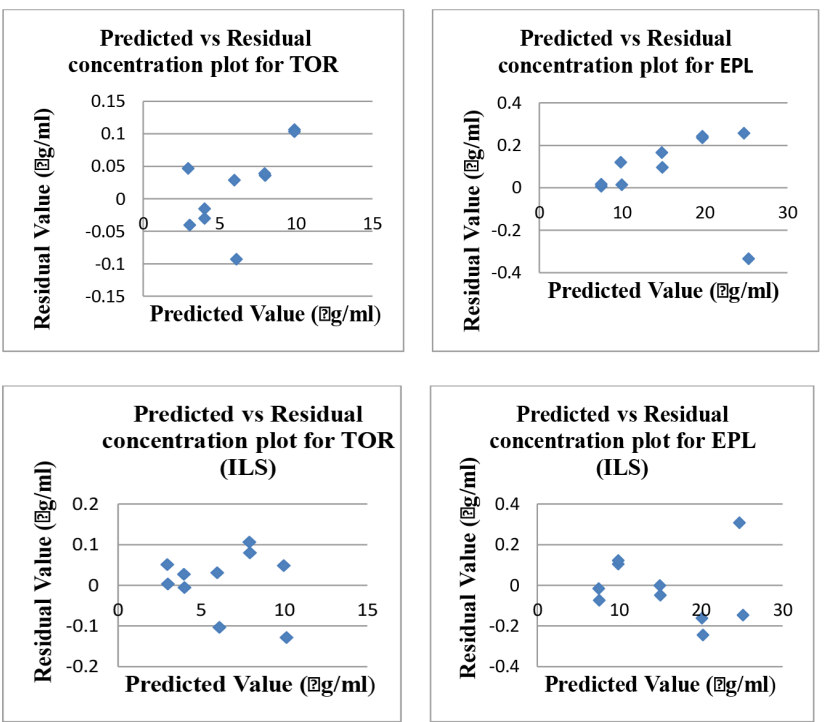

Figure 5: CLS - Expected vs. Residual Concentration of TOR and EPL, ILS - Expected vs. Residual Concentration of TOR and EPL. to a powder. These tablet powder weighed accurately by taking the quantity equivalent to about $25 \mathrm{mg}$ of EPL and $10 \mathrm{mg}$ of TOR and transferred to $25 \mathrm{~mL}$ volumetric flask and dissolved in $10 \mathrm{~mL}$ of methanol. Then the sample solution was sonicated for 15-20 min and volume was adjusted with methanol and the solution was filtered by using a whatman filter paper no.42. Further dilutions were made to get the solution containing $25 \mu \mathrm{g} / \mathrm{mL}$ of EPL and $10 \mu \mathrm{g} / \mathrm{mL}$ of TOR. The assay was performed thrice for tablet formulation. The assay results for different brands are shown in Table 6. Summary of parameters for Classical Least Square and Inverse Least Square are depicted in Table 7.

\section{CONCLUSION}

Many drugs are used in combinations to improve the therapy of various ailments. The estimation of individual drugs from their combined dosage forms becomes a major challenge with respect time requirement for estimation and complexity of mixtures. The chemometric methods are cost effective compare to other methods and these methods are performed by using spectrophotometer and there is no need of prior separation of components. The developed chemometric assisted spectrophotometric methods are prompt and applicable for the simultaneous estimation of TOR and EPL from their mixed solutions and pharmaceutical

\begin{tabular}{|c|c|c|c|c|c|c|}
\hline \multicolumn{7}{|c|}{ For CLS method } \\
\hline \multirow[t]{2}{*}{ Formulation } & \multicolumn{2}{|c|}{$\begin{array}{c}\text { Actual concentration } \\
\mathrm{mg} / \text { tablet }\end{array}$} & \multicolumn{2}{|c|}{$\begin{array}{c}\text { Amount obtained } \\
\mathrm{mg} / \mathrm{tablet}\end{array}$} & \multirow[t]{2}{*}{$\%$ TOR \pm S.D. $(n=3)$} & \multirow[t]{2}{*}{$\%$ EPL \pm S.D. $(n=3)$} \\
\hline & TOR & EPL & TOR & EPL & & \\
\hline PLANEP T 10 & 10 & 25 & 9.914 & 24.92 & $99.14 \pm 0.1192$ & $99.68 \pm 0.1343$ \\
\hline DYTORE E & 10 & 25 & 9.96 & 25.06 & $99.66 \pm 0.1393$ & $100.27 \pm 0.0637$ \\
\hline EPNONE T & 10 & 25 & 9.974 & 24.92 & $99.74 \pm 0.1152$ & $99.66 \pm 0.2236$ \\
\hline EPTUS T & 10 & 25 & 10.05 & 25.08 & $100.52 \pm 0.0772$ & $100.34 \pm 0.0890$ \\
\hline EXENTA T & 10 & 25 & 9.98 & 25.13 & $99.76 \pm 0.14449$ & $100.53 \pm 0.2617$ \\
\hline
\end{tabular}

\begin{tabular}{|c|c|c|c|c|c|c|}
\hline \multirow{2}{*}{ Formulation } & \multicolumn{9}{|c|}{$\begin{array}{c}\text { Actual concentration } \\
\text { mg/tablet }\end{array}$} & \multicolumn{2}{c|}{$\begin{array}{c}\text { Amount obtained } \\
\text { mg/tablet }\end{array}$} & \multirow{2}{*}{$\%$ TOR \pm S.D. $(\boldsymbol{n}=3)$} & \% EPL \pm S.D. $(\boldsymbol{n}=3)$ \\
\cline { 2 - 6 } & TOR & EPL & TOR & EPL & & $100.24 \pm 0.3439$ \\
\hline PLANEP T 10 & 10 & 25 & 9.97 & 25.06 & $99.76 \pm 0.1156$ & $99.71 \pm 0.7490$ \\
\hline DYTORE E & 10 & 25 & 9.90 & 24.92 & $99.06 \pm 0.0991$ & $100.08 \pm 0.1892$ \\
\hline EPNONE T & 10 & 25 & 10.03 & 25.02 & $100.34 \pm 0.0466$ & $100.66 \pm 0.1967$ \\
\hline EPTUS T & 10 & 25 & 10.09 & 25.17 & $100.92 \pm 0.1037$ & $100.20 \pm 0.1414$ \\
\hline EXENTA T & 10 & 25 & 9.91 & 25.05 & $99.10 \pm 0.1236$ & \\
\hline
\end{tabular}


Table 7: Summary of Parameters for CLS and ILS methods.

\begin{tabular}{|c|c|c|c|c|c|c|}
\hline \multirow[t]{2}{*}{ Sr. No. } & \multirow{2}{*}{\multicolumn{2}{|c|}{$\begin{array}{l}\text { Parameters } \\
\text { Torsemide }\end{array}$}} & \multicolumn{2}{|c|}{ CLS } & \multicolumn{2}{|c|}{ ILS } \\
\hline & & & Eplerenone & Torsemide & Eplerenone & \\
\hline 1 & \multicolumn{2}{|c|}{ Calibration design set } & \multicolumn{4}{|c|}{15} \\
\hline 2 & \multicolumn{2}{|c|}{ Validation design set } & \multicolumn{4}{|c|}{10} \\
\hline 3 & \multicolumn{2}{|c|}{ Spectral region } & \multicolumn{4}{|c|}{$240-300 \mathrm{~nm}$} \\
\hline 4 & \multicolumn{2}{|c|}{ Linearity range $(\mu \mathrm{g} / \mathrm{mL})$} & $3-10$ & $7.5-25$ & $3-10$ & $7.5-25$ \\
\hline 5 & \multicolumn{2}{|c|}{ RMSEP } & 0.06069 & 0.05097 & 0.05097 & 0.58312 \\
\hline 6 & \multicolumn{2}{|c|}{ \% Recovery (Mean) } & 99.89 & 99.44 & 99.72 & 100.06 \\
\hline \multirow[t]{5}{*}{7} & \multirow[t]{5}{*}{ Assay } & Planep T & 9.914 & 24.92 & 9.97 & 25.06 \\
\hline & & Dytore $\mathrm{E}$ & 9.96 & 25.06 & 9.90 & 24.92 \\
\hline & & Epnone T & 9.974 & 24.92 & 10.03 & 25.02 \\
\hline & & Eptus T & 10.05 & 25.08 & 10.09 & 25.17 \\
\hline & & Exenta T & 9.98 & 25.13 & 9.91 & 25.05 \\
\hline 8 & \multicolumn{2}{|c|}{$\operatorname{LOD}(\mu \mathrm{g} / \mathrm{mL})$} & 0.1822 & 0.1359 & 0.0630 & 0.0488 \\
\hline 9 & \multicolumn{2}{|c|}{ LOQ $(\mu \mathrm{g} / \mathrm{mL})$} & 0.5523 & 0.4118 & 0.1909 & 0.1481 \\
\hline
\end{tabular}

tablets dosage forms. The two chemometric methods; CLS and ILS were found to be accurate, precise, fast and economical for the multicomponent estimation. The proposed methods were validated according to ICH guideline and found suitable for estimation of the two drugs in quality control laboratories.

\section{ACKNOWLEDGEMENT}

The authors are thankful to Sun Pharmaceuticals, India and Lupin Laboratories, India for providing gift samples of Torsemide and Eplerenone as pure drugs. Authors are also thankful to ROFEL Shri G. M. Bilakhia College of Pharmacy, Vapi for making available the facilities to carry out the research work.

\section{CONFLICT OF INTEREST}

The authors declare no conflict of interest.

\section{ABBREVIATIONS}

TOR: Torsemide; EPL: Eplerenone; CLS: Classical least square; ILS: Inverse least square; $\boldsymbol{\mu g}$ : microgram; nm: Nanometre; HPLC: High performance liquid chromatography; HPTLC: High performance thin layer chromatography; LC-MS: Liquid chromatographyMass spectrometer.

\section{REFERENCES}

1. Dinç E, Baleanu D. Spectrophotometric quantitative determination of cilazapril and hydrochlorothiazide in tablets by Chemometric methods. J Pharm Biomed Anal. 2002;30(3):715-23. doi: 10.1016/s0731-7085(02)00359-x, PMID 12367697.
2. Bhamre P, Pathak A, Rajput S. Simultaneous determination of doxylamine succinate, pyridoxine hydrochloride and folic acid by Chemometric spectrophotometry. Int J Pharm Biol Sci. 2013;4(1):738-49.

3. Rang HP, Dale MM, Ritter JM, Flower RJ. Pharmacology. 6th ed. Churchill Livingstone; 2007. p. 309-10.

4. Tripathi KD. Essentials of medical pharmacology. 6th ed. Jaypee brother's Medical publisher (p) Itd.; 2010. p. 184-5.

5. Available from: https://pubchem.ncbi.nlm.nih.gov/compound/torsemide, accessed on date: 10/03/2017 [cited 26/11/2021].

6. Available from: https://pubchem.ncbi.nlm.nih.gov/compound/Eplerenone, accessed on date: 10/03/2017 [cited 26/11/2021].

7. United States Pharmacopoeia 30- national formulary. 2007;25:3385.

8. Indian pharmacopoeia. Government of India. Minist Health Fam Welf. 2014;II:1668-9.

9. Satyanarayana PV, Adilakshmi GV. RP-HPLC method development validation and forced degradation studies for simultaneous estimation of torsemide and spironolactone in tablet dosage form. Am J Pharm Tech Res. 2015;5(4):625-37.

10. Sharma K, Gupta S, Sharma Y. Method Development and Validation for Estimation of torsemide in Tablet Dosage form by RP-HPLC and UV spectrophotometry. Pharmatutor. 2016.

11. Laxman R, Acharya A, Jain V, Bhardwaj S, Jain D. Development and validation of RP-HPLC and ultraviolet spectrophotometric methods for simultaneous determination of Spiranolactone and torsemide in Pharmaceutical dosage form. Int J Res Ayurveda Pharm. 2010;1(2):459-67.

12. E. Zaazaa H, S. Abbas S, M. Essam H, G. El-Bardicy M. Development and validation of stability-indicating methods for determination of torsemide. Bull Chem Soc Eth;30(1). doi: 10.4314/bcse.v30i1.2.

13. Sarkate AP, Shinde SD, Sarkate AP, Sangshetti JN. Stability indicating HPLC method for determination of torsemide in bulk drug and pharmaceutical dosage form. Res J Pharmacol. 2015;6(4):749.

14. Zhang L, Wang R, Tian $\mathrm{Y}$, Zhang Z. Determination of torasemide in human plasma and its bioequivalence study by high-performance liquid chromatography with electrospray ionization tandem mass spectrometry. J Pharm Anal. 2016;6(2):95-102. doi: 10.1016/j.jpha.2015.11.002, PMID 29403968.

15. Sharma S, Sharma MC, Kohli DV, Chaturvedi SC. Isocratic reverse phase HPLC estimation method of torsemide and spironolactone in pharmaceutical combined dosage form. Optoelectron Adv Mater Rapid Commun. 2010;4(2):234-7. 
16. Patel RD, Maheshwari DG. RP-HPLC method for the estimation of torsemide and amiloride $\mathrm{HCl}$ in their combined dosage form. Indo-. Am J Pharm. 2014;4(04)

17. Satyanarayana PVV, Adilakshmi GV. RP-HPLC method development validation and forced degradation studies for simultaneous estimation of torsemide and spironolactone in tablet dosage form. Am J Pharm Tech Res. 2015;5(4):626-37.

18. Rane VP, Patil KR, Sangshetti JN, Yeole RD, Shinde DB. Stability-indicating RP-HPLC method for analysis of eplerenone in the bulk drug and in a pharmaceutical dosage form. Acta Chromatogr. 2009;21(4):619-29. doi: 10.1556/AChrom.21.2009.4.8.

19. Sharma MC, Sharma S, Kohli DV, Sharma AD. Validated TLC Densitometric method for Quantification of torsemide and spironolactone in Bulk drug and in Tablet dosage form. Pharm Chem. 2010;2(1):121-6.

20. Mahajan BH, Kekar N, Shah S. Quantitative Determination of eplerenone in Bulk drug and tablet Dosage form by TLC. Int J Pharm Life Sci. 2011;2(1):502-5.

21. Bus-Kwasnik K, Filist M, Rudzki PJ. Environmentally friendly LC/ MS determination of eplerenone in human plasma. Acta Pol Pharm. 2016;73(6):1487-93. PMID 29634102.

22. Wen-juan Q, Li D, Ai-dong W, Bin G, Ye L, Chang-hong YUN, et al. Establishment of HPLC-ESI-MS method for the determination of eplerenone in human plasma and its pharmacokinetics. Acta Pharmacol Sin. 2009;44(7):771-7.

23. Krishna MV, Sankar DG. Simple spectrophotometric determination of torsemide in bulk drug and in formulations. E-journal of chemistry. 2008;5(3):473-8.
24. Bhadja SA, Chhalotiya UK, Shah DA, Mehta FA, Bhatt K. Simultaneous estimation of torsemide and amiloride hydrochloride in their pharmaceutical dosage form by Dual wavelength UV spectroscopic method. Adv J Pharm Life Sci Res. 2014;2(1):21-8.

25. Shaniya P, Hopsebah NJ, Khasim MD, Kumar AA. Dissolution Method Development and Validation of eplerenone tablet by UV Spectroscopy. Ind-Ame. J Pharm Sci. 2016;3(4):351-7.

26. Shailaja B, Swarna K, Afreen M, Ashok KA. A rapid assay method development and validation for the estimation of eplerenone in tablets by UV spectrophotometry. Int J Pharm Pharm Sci. 2015;7(9):327-30.

27. Patel KS, Bendale A, Luhar SV, Narkhede SB. Development and validation of RP-HPLC method for the simultaneous estimation of eplerenone and torsemide in pharmaceutical dosage form. J PharmSci Bio-Sci Res. 2016;6(3):283-90.

28. Hinge MA, Patel D, Patel A. Development and Validation of UV spectrophotometric method for Simultaneous estimation of torsemide and eplerenone in Bulk drugs and combined dosage forms. Int J Pharm Sci Rev Res. 2019;56(2):63-7.

29. Kranthi KK, Jhansi GLB, Ganesh K. Method development and Validation for the Simultaneous Estimation of eplerenone and torsemide using RPHPLC. Int J Pharm Res Novel Sci. 2018;3(2):443-9.

30. Patel RB, Patel BR, Patel JG, Patel VS. Stability indicating RP-HPLC method development and Validation for Simultaneous estimation of eplerenone and torsemide in Tablet dosage form. World J Pharm Pharm Sci. 2017;6(5):1397-406.

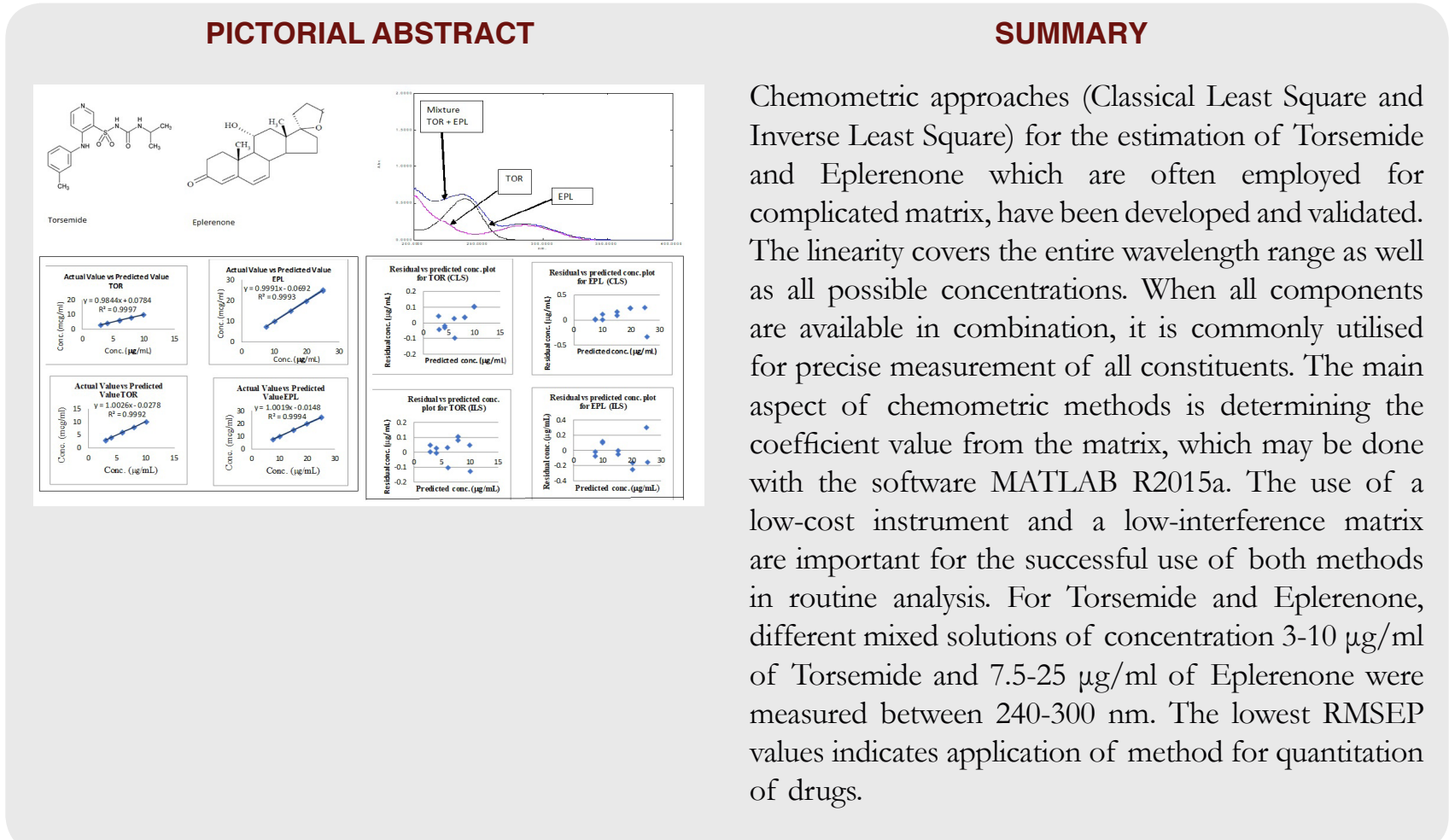




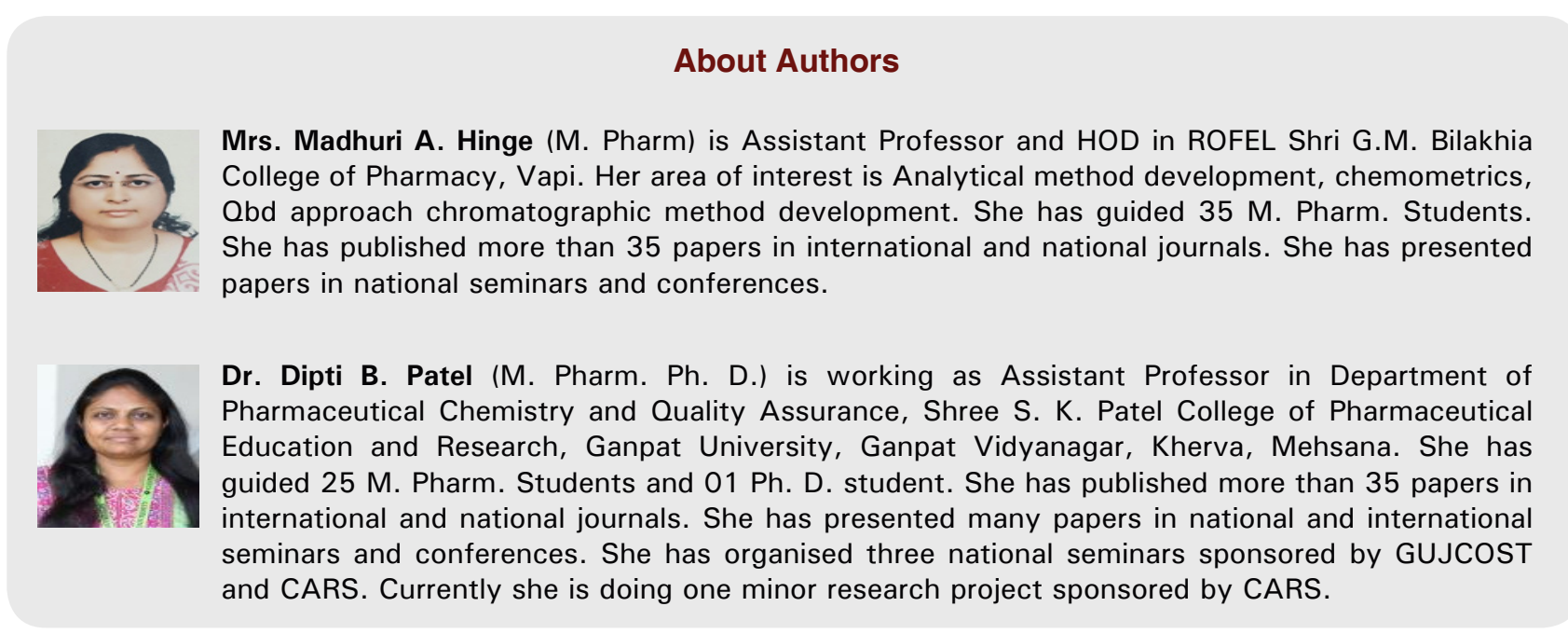

Cite this article: Madhuri A, Patel D. Chemometric Assisted Spectrophotmetric Method Development for Evaluation of Torsemide and Eplerenone in their Combined Tablet Dosage Forms. Indian $\mathrm{J}$ of Pharmaceutical Education and Research. 2022;56(1):255-63. 